\title{
Leukaemia and non-Hodgkin's lymphoma: incidence in children and young adults resident in the Dounreay area of Caithness, Scotland in 1968-91
}

\author{
Roger J Black, Linda Sharp, Elaine F Harkness, Patricia A McKinney
}

\begin{abstract}
Study objective - To review the incidence of leukaemia and non-Hodgkin's lymphoma in children and young adults in the area less than $25 \mathrm{~km}$ from the Dounreay nuclear installation and the remainder of the Kirkwall postcode area in the full time period for which data are now available (1968-91), and to determine whether the excess incidence reported in the period up to 1984 has continued in subsequent years.

Design - Geographical incidence study. Setting - The Kirkwall postcode area of Scotland.

Subjects - Children and young adults resident in the area in the period 1968-91. Main results - Observed numbers of cases of leukaemia and non-Hodgkin's lymphoma and observed to expected ratios with expected numbers based on Scottish national rates were determined. In 1968-91, 12 cases were observed compared with 5.2 expected in the zone $<25 \mathrm{~km}$ from the Dounreay plant $(p=0.007)$. In the latest period, 1985-91, which has not previously been examined, four cases were observed compared with 1.4 expected $(p=0.059)$.

Conclusion - The observation of an excess of borderline statistical significance in 1985-91 following the substantial excess incidence which occurred in the early 1980 s suggests that the incidence of leukaemia and non-Hodgkin's lymphoma in this area should continue to be a matter of concern. The phenomenon of high incidences of childhood and young adult leukaemia and lymphoma near some nuclear installations in isolated areas is yet to be explained, but certain aspects of the data examined in the present report are consistent with the hypothesis of an infectious aetiology for leukaemia in very young children.
\end{abstract}

\section{( $\mathcal{F}$ Epidemiol Community Health 1994;48:232-236)}

In 1986 the Information and Statistics Division of the Scottish Health Service Common Services Agency (ISD) was asked to provide information on the incidence of cancer in the population living near the Dounreay nuclear reprocessing plant in Caithness, Scotland. This was prompted by a public local inquiry into a proposed development of the plant. ${ }^{1}$ With the exception of a higher than expected incidence of leukaemia in the 0-24 age group, no general excess of cancer was found. ${ }^{2}$ The findings in relation to leukaemia were referred by the inquiry reporter to the Committee on Medical Aspects of Radiation in the Environment (COMARE) and formed the basis of the committee's second report. ${ }^{3}$

Six cases were observed among people aged 0-24 years resident within $25 \mathrm{~km}$ of Dounreay in the period 1968-84 compared with 3.0 expected on the basis of Scottish national rates (observed to expected ratio $(\mathrm{O} / \mathrm{E}) 2 \cdot 0$, $\mathrm{p}=0.08)$. All six cases occurred in the period 1979-84 (O/E 6.5, p<0.01). COMARE concluded that 'the incidence of leukaemia amongst young people from the Dounreay area was substantially above the national expectation for the period 1968-84' and that 'the distribution of cases over time, although unexpected and therefore difficult to evaluate, increases the concern about leukaemia incidence in this area'.

Further epidemiological investigations were recommended, including a study which compared the incidence of leukaemia and other cancers in a cohort of children born locally with those who attended school in the area but had been born elsewhere, ${ }^{4}$ and a case-control study which examined a number of possible risk factors for leukaemia. ${ }^{5}$ Both of these studies included cases of leukaemia and of nonHodgkin's lymphoma who were registered after 1984, the last year of data examined in the second COMARE report, but details of these new cases have not previously been reported in the context of a formal geographical study of incidence. Analysis of the recent incidence of childhood cancer near Sellafield, the other main site of nuclear reprocessing in the United Kingdom, has been conducted by Draper et al. ${ }^{6}$

The aim of this paper is to present incidence data for the period 1985-91 and for the full period for which reliable incidence data for Scotland are now available, 1968-91. While the authors are aware of the limitations of studies involving very small numbers of cases, it is felt that a formal update of the second COMARE report is justified by the considerable scientific and public interest in the incidence of leukaemia and non-Hodgkin's lymphoma in young people in this part of Scotland.

Data and methods

CASE ASCERTAINMENT AND VALIDATION

The main source of information about the 
incidence of cancer in Scotland is the Scottish National Cancer Registry. The ascertainment rate for new cases of cancer in children in Scotland is thought to be in excess of $90 \%$. Registrations of leukaemia in children and young adults in Scotland have been subject to particular scrutiny in order to ensure completeness and accuracy. Glass et al compared registrations in 1968-82 with hospital discharge and mortality records in an attempt to trace possible missed cases. All cases were then submitted for panel review of diagnosis and addresses of cases were checked from case notes and postcoded. A further review of cases of leukaemia and also of non-Hodgkin's lymphoma in the Dounreay area was conducted by members of COMARE. ${ }^{3}$ This showed that some of the cases previously registered as nonHodgkin's lymphoma would have been classified as leukaemia using contemporary diagnostic criteria. The original validation study of leukaemia in 1968-82 is now being supplemented by a case finding and validation exercise covering all cases of childhood cancer in Scotland in the period 1975-90. This is the first stage of a study of the incidence of childhood cancer near all nuclear installations in Scotland. The original cancer registration records have been matched against those of the National Registry of Childhood Tumours, ${ }^{7}$ the database held by the Medical Research Council's Clinical Trials Service Unit at the Rad-

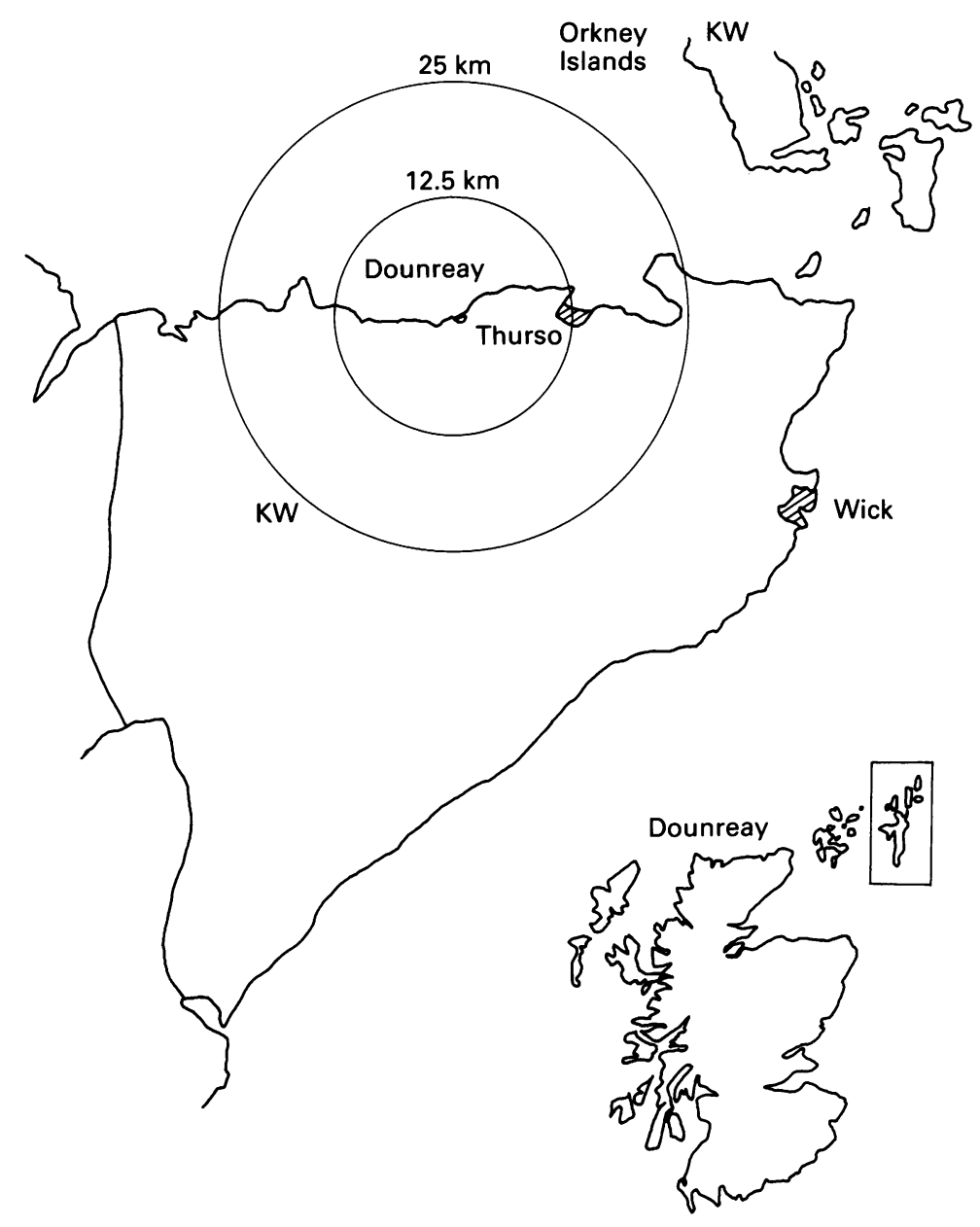

Figure 1 Study areas. cliffe Infirmary, Oxford, and hospital discharge records (SMR1) held by ISD.

Potential cases were followed up by checking demographic details, particularly postcodes, and by confirmation of diagnosis or, where necessary, panel review of diagnoses. This work in respect of leukaemia is now complete and the validated information has been used in the data analysis for this report. A proportion of the non-Hodgkin's lymphoma cases have not yet been validated and only basic cancer registration data have been included in the analysis. A full report of the methods and outcome of this validation exercise will be published elsewhere. All cases in the 0-14 age group diagnosed since 1 January 1991 have been admitted to the Scottish Case Control Study of Childhood Cancer and are validated as a matter of routine. Details of leukaemias and non-Hodgkin's lymphomas diagnosed in persons aged 15-24 years have been extracted from the records of the cancer registry. In order to maintain the comparability of incidence data for the study areas with data for other areas of Scotland, the present report considers only the combined incidence of leukaemia and non-Hodgkin's lymphoma.

\section{POPULATION DATA}

Population estimates for the study areas defined in the earlier reports were based on the censuses of 1971 and $1981 .{ }^{23}$ In Scotland, the geography of the 1991 census permits direct matching of output areas with 1981 and henceforth also with the study areas defined in these earlier reports. Age specific, usually resident, population counts were extracted from the small areas statistics for the censuses of 1971, 1981, and 1991 and linear interpolation was used to calculate intercensal population estimates for the study areas. Populations used in calculating background rates were drawn from mid-year population estimates for Scotland. ${ }^{9}$

\section{STATISTICAL METHODS}

The form of presentation used in the present paper follows that adopted in the second COMARE report. ${ }^{3}$ The overall study area was the KW (Kirkwall) postcode area which includes Caithness District, part of Sutherland District, and the Orkney Islands (fig 1). Study zones were defined in terms of distance from the Dounreay site. The 'full Dounreay area' was defined as the area less than $25 \mathrm{~km}$ from the site and includes an 'inner zone' (less than $12.5 \mathrm{~km}$ from the site) and an 'outer zone' (from $12.5 \mathrm{~km}$ to less than $25 \mathrm{~km}$ from the site). The 'full neighbouring area' was defined as the remainder of the $\mathrm{KW}$ postcode area, including the 'mainland residue' (the mainland $\mathrm{KW}$ area $25 \mathrm{~km}$ or more from the site) and Orkney.

Data for the time periods 1968-91 and 198591 and the age groups $0-24$ and $0-14$ were tabulated separately, again in the manner of the second COMARE report. Observed numbers of cases were compared with expected numbers calculated by applying age specific Scottish national rates for leukaemia and nonHodgkin's lymphoma, based on the validation 
Table 1 Census population counts of those aged 0-24 years for the study areas: 1971, $1981,1991$.

\begin{tabular}{lccc}
\hline & \multicolumn{2}{c}{ Census } & \\
\cline { 2 - 4 } Study area & 1971 & 1981 & 1991 \\
\hline Full Dounreay area: & 6334 & 5834 & 4896 \\
Inner Zone & 3157 & 3101 & 2542 \\
Outer Zone & 3177 & 2733 & 2354 \\
Full neighbouring area & 13771 & 13350 & 12411 \\
Mainland residue KW & 7685 & 6810 & 6048 \\
Orkney & 6086 & 6540 & 6363 \\
\hline Total & 20105 & 19184 & 17307 \\
\hline
\end{tabular}

Table 2 Details of leukaemia and non-Hodgkin's lymphoma registrations among those aged 0-24 years for the full period 1968-91. Year of diagnosis, validated diagnosis, age, sex, and zone of residence at diagnosis are given.

\begin{tabular}{llcll}
\hline $\begin{array}{l}\text { Year of } \\
\text { diagnosis }\end{array}$ & Diagnosis* & $\begin{array}{c}\text { Age at } \\
\text { diagnosis } \\
(y)\end{array}$ & Sex & $\begin{array}{l}\text { Zone of } \\
\text { residence }\end{array}$ \\
\hline 1968 & ALL & 2 & M & Orkney \\
1969 & ALL & 2 & $\mathrm{~F}$ & Mainland residue KW \\
1969 & ALL & 2 & $\mathrm{M}$ & Mainland residue KW \\
1970 & Lymphoid leukaemia & 2 & $\mathrm{M}$ & Inner zone \\
1970 & NHL & 2 & $\mathrm{~F}$ & Mainland residue KW \\
1974 & NHL & 2 & $\mathrm{M}$ & Mainland residue KW \\
1978 & AML & 11 & $\mathrm{~F}$ & Orkney \\
1979 & ALL & 1 & $\mathrm{M}$ & Mainland residue KW \\
1979 & ALL & 8 & $\mathrm{M}$ & Mainland residue KW \\
1980 & ALL & 2 & $\mathrm{~F}$ & Inner zone \\
1980 & Lymphoid leukaemia & 2 & $\mathrm{M}$ & Inner zone \\
1980 & AML & 9 & $\mathrm{~F}$ & Outer zone \\
1981 & Acute monocytic leukaemia & 2 & $\mathrm{M}$ & Outer zone \\
1983 & AML & 8 & $\mathrm{~F}$ & Inner zone \\
1983 & ALL & 14 & $\mathrm{~F}$ & Inner zone \\
1984 & ALL & 23 & $\mathrm{~F}$ & Inner zone \\
1984 & ALL & 4 & $\mathrm{~F}$ & Orkney \\
1986 & NHL & 12 & $\mathrm{~F}$ & Inner zone \\
1988 & ALL & 15 & $\mathrm{M}$ & Inner zone \\
1988 & NHL & 21 & $\mathrm{M}$ & Outer zone \\
1988 & ALL & 4 & $\mathrm{~F}$ & Mainland residue KW \\
1990 & ALL & 2 & $\mathrm{M}$ & Outer zone \\
1990 & ALL & 2 & M & Mainland residue KW \\
1991 & ALL & 2 & $\mathrm{~F}$ & Orkney \\
1991 & ALL & 4 & $\mathrm{M}$ & Orkney \\
\hline
\end{tabular}

*ALL = acute lymphoblastic leukaemia; $\mathrm{AML}=$ acute myeloid leukaemia; $\mathrm{NHL}=$ nonHodgkin's lymphoma

Table 3 Numbers of registrations of leukaemia and non-Hodgkin's lymphoma, observed to expected ratios $(O / E)$, and Poisson probabilities $(p)$ by area of residence and age at diagnosis for the full period 1968-91.

\begin{tabular}{lccccccc}
\hline & $0-14$ years & \multicolumn{7}{c}{$0-24$ years } \\
\cline { 2 - 8 } Study area & $\begin{array}{l}\text { Observed } \\
\text { registrations }\end{array}$ & $O / E$ & $p$ & $\begin{array}{l}\text { Observed } \\
\text { registrations }\end{array}$ & $O / E$ & $p$ \\
\hline Full Dounreay area: & 9 & 2.58 & 0.010 & 12 & 2.32 & 0.007 \\
$\quad$ Inner Zone & 6 & 3.29 & 0.011 & 8 & 2.97 & 0.006 \\
Outer Zone & 3 & 1.80 & 0.233 & 4 & 1.61 & 0.239 \\
Full neighbouring area: & 13 & 1.61 & 0.068 & 13 & 1.09 & 0.412 \\
$\quad$ Mainland residue KW & 8 & 1.92 & 0.062 & 8 & 1.29 & 0.281 \\
Orkney & 5 & 1.27 & 0.356 & 5 & 0.87 & 0.676 \\
\hline Total & 22 & 1.90 & 0.004 & 25 & 1.46 & 0.042 \\
\hline
\end{tabular}

Table 4 Numbers of registrations of leukaemia and non-Hodgkin's lymphoma, observed to expected ratios $(O / E)$ and Poisson probabilities ( $p)$ by area of residence and age at diagnosis for the latest period 1985-91.

\begin{tabular}{lllllll}
\hline & \multicolumn{7}{c}{\begin{tabular}{l}
$0-14$ years \\
\cline { 2 - 7 }
\end{tabular}} & $\begin{array}{l}\text { Observed } \\
\text { registrations }\end{array}$ & $O / E$ & $p$ & $\begin{array}{l}\text { Observed } \\
\text { registrations }\end{array}$ & $O / E$ & $p$ \\
\hline Study area & 2 & 2.08 & 0.251 & 4 & 2.76 & 0.059 \\
\hline Full Dounreay area: & 2 & 1.96 & 0.400 & 2 & 2.65 & 0.175 \\
$\quad$ Inner Zone & 1 & 2.21 & 0.364 & 2 & 2.88 & 0.153 \\
Outer Zone & 1 & 1.60 & 0.243 & 4 & 1.10 & 0.495 \\
Full neighbouring area: & 4 & 1.65 & 0.341 & 2 & 1.12 & 0.532 \\
$\quad$ Mainland residue KW & 2 & 1.55 & 0.370 & 2 & 1.07 & 0.556 \\
Orkney & 2 & 1.73 & 0.138 & 8 & 1.57 & 0.144 \\
\hline Total & 6 & & & &
\end{tabular}

study described above. In order to maintain compatibility with the second COMARE report, ${ }^{3}$ no adjustments were made for socioeconomic variables or urban-rural status. The $p$ values shown denote the probability, based on the Poisson distribution, of observing $n$ or more cases, given the number expected.

\section{Results}

Population counts for the study areas from the censuses of 1971, 1981, and 1991 are shown in table 1 . With the exception of Orkney, there has been a decline in the population aged 0-24 years of the KW area between 1971 and 1991. For example, the population of $0-24$ year olds in the zone within $25 \mathrm{~km}$ of Dounreay fell from 6334 to 5834 to 4896 in successive censuses. Table 2 summarises details of all cases of leukaemia and non-Hodgkin's lymphoma in the $0-24$ age group resident in the study areas in the period 1968-91. Eight cases of leukaemia and non-Hodgkin's lymphoma were registered in the 0-24 age group in 1985-91, bringing the incidence in the full period 196891 to 25 . The table includes diagnostic information based on the most recent review.

The distribution of cases between study areas in the full period 1968-91 is shown in table 3. Twelve cases in the $0-24$ age group occurred in the area within $25 \mathrm{~km}$ of Dounreay $(\mathrm{O} / \mathrm{E} 2 \cdot 3, \mathrm{p}=0.007)$ and 13 in the remainder of the $\mathrm{KW}$ area and Orkney $(\mathrm{O} / \mathrm{E} 1 \cdot 1, \mathrm{p}=0.412)$. The observed cases exceeded expectation in both the inner and outer zones of the area within $25 \mathrm{~km}$ of Dounreay, although the excess was statistically significant only in the inner zone $(\mathrm{O} / \mathrm{E} 3 \cdot 0, \mathrm{p}=0.006)$. Table 4 shows that of the eight cases in the most recent time period, four were resident within $25 \mathrm{~km}$ of Dounreay $(\mathrm{O} / \mathrm{E} 2 \cdot 8, \mathrm{p}=0.059)$ and the remaining four in the 'full neighbouring area' $(\mathrm{O} / \mathrm{E}$ $1 \cdot 1, p=0.495)$. Thus, while the numbers of cases observed exceeded expectation in all single areas and combinations of areas, none of these was statistically significant. Tables 3 and 4 also show equivalent comparisons for the age group 0-14. The results are broadly similar to those for the 0-24 age group. In the 'full Dounreay area', nine of the total 12 cases were aged 0-14 while in the 'full neighbouring area' all cases were aged $0-14$ years.

Figure 2 shows the age specific incidence rates of leukaemia and non-Hodgkin's lymphoma for the 'full Dounreay area', the 'full neighbouring area', and the whole of Scotland for the full time period 1968-91. Children aged $0-4$ years at diagnosis resident in both the 'full Dounreay area' (rate 19.34 per 100000 ) and the 'full neighbouring area' (18.04 per 100000 ) exhibited rates more than twice those recorded for all Scotland (6.52 per 100000$)$. The incidence in each of the older age groups for the 'full Dounreay area' exceeds that for Scotland as a whole. For the 'full neighbouring area', incidence rates in the 5-9 and 10-14 age groups are lower than the all Scotland figures. No cases aged 15 years or older were diagnosed in this area. 


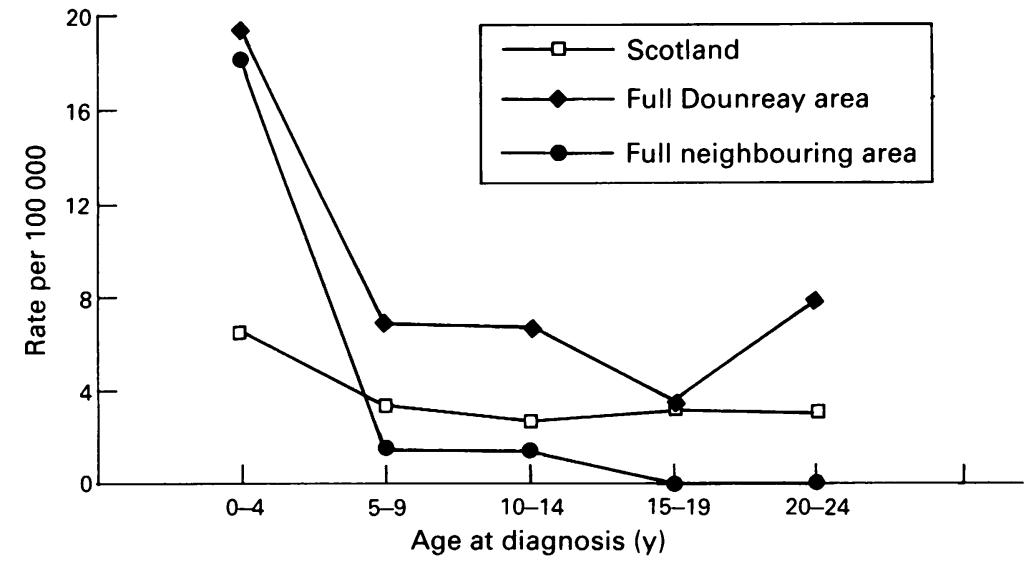

Figure 2 Incidence of leukaemia and non-Hodgkin's lymphoma by age at diagnosis ie to 'full Dounreay area', 'full neighbouring area', and Scotland, 1968-91.

\section{Discussion}

In observational studies of disease incidence in small geographical areas, the categorisation of data in terms of age and diagnostic groups and spatial and temporal boundaries invites the criticism that results may be unreliable because of the particular categorisation chosen or even that the categorisation was not made independently of the data. A more fundamental difficulty arises when the motivation for such a study is pre-existing concern about disease incidence in a particular area based, for example, on a survey of many small areas or on the perceptions of local residents. In the case of the original Dounreay study, this latter point does not apply since the study was undertaken in order to provide information to the public inquiry initiated following a proposal to redevelop the Dounreay site. The categorisation of data in the original study was arbitrary and subdivisions of the spatial and temporal boundaries were used in order to avoid reliance on a single set of boundaries which might misrepresent the data. In their consideration of the Dounreay incidence data, COMARE $^{3}$ chose to base their conclusions on the most conservative categorisation of the data: the area less than $25 \mathrm{~km}$ from Dounreay and the full time period 1968-84. On the same basis, the main conclusion from the present study is that there was a statistically significant excess incidence of leukaemia and non-Hodgkin's lymphoma in the area less than $25 \mathrm{~km}$ from Dounreay in the full period 1968-91. In both the second COMARE report ${ }^{3}$ and the subsequent study of the incidence of leukaemia and non-Hodgkin's lymphoma in birth and schools cohorts in the Dounreay area ${ }^{4}$ it was noted that the most unusual feature of the series of cases was their concentration in the most recent years studied. The findings of the present study in relation to the period 1985-91 reinforce concern about this aspect of the data.

Following reports of high incidences of leukaemia near both Sellafield ${ }^{10}$ and Dounreay $^{3}$, two very detailed case-control studies of possible risk factors have now been conducted in these areas. At Seascale, near Sellafield, Gardner et $a l^{11}$ found a significant association between leukaemia and non-Hodgkin's lymphoma in children and paternal preconceptional occupational exposure to ionising radiation. This association was not found in a comparable study of cases and controls in the Dounreay area in the period up to $1986 .{ }^{5}$ Indeed, only two of the eight cases with leukaemia in the area within $25 \mathrm{~km}$ of Dounreay had fathers who had worked at the plant at the time of the child's conception. The only finding of potential significance in the Dounreay study was a higher proportion of parents of cases than of controls who reported recreational use of the beaches near Dounreay, although the strength of evidence for this association was very weak.

Early reports of leukaemia excesses near Sellafield and Dounreay led Kinlen et al to test the hypothesis that risk of leukaemia in isolated rural areas was raised following large influxes of population. A series of studies ${ }^{12} 13$ showed that in particular circumstances, such as the development of new towns in previously isolated areas, high rates of leukaemia were associated with rapid population growth. These data were interpreted as evidence of an aetiology involving infectious exposures for childhood leukaemia. Kinlen ${ }^{12}$ reported incidentally that the burgh in Scotland with the greatest proportional increase in population size $(147 \%)$ between 1951 and 1961 was Thurso. This was due to the development of the Dounreay plant leading up to the start of operations in 1958. However, the temporal distribution of leukaemia cases near Dounreay, which appeared mainly after 1979 , is not consistent with Kinlen's hypothesis of population mixing leading to increased incidence of childhood leukaemia as specified in these early studies. More recently Kinlen has studied population mixing due to the large numbers of workers from many areas of Scotland employed away from home in the North Sea offshore oil industry. ${ }^{14}$ In areas categorised as rural with high proportions of their male adult populations employed in the oil industry there was a significant excess incidence of leukaemia and non-Hodgkin's lymphoma in the age group $0-24$ in the 'early post-mixing period' 1979-83 (O/E 1-4). This was mainly due to an approximately twofold excess in children aged less than 5 years (O/E 1.9). The Dounreay area was included in this category, and Kinlen has suggested that the local excess of leukaemia and non-Hodgkin's lymphoma in young people previously reported in the period 197984 was due to temporary effects of intense population mixing among the adult population employed away from home in the oil industry in an area in which the proportion of such workers had previously been low. In rural, high oil worker areas in the 'later post-mixing period', 1984-88, there was a small excess which was not statistically significant $(\mathrm{O} / \mathrm{E}$ $1 \cdot 1)$. The results of this paper have shown that the local excess incidence of leukaemia and non-Hodgkin's lymphoma near Dounreay has continued into the 'later post-mixing period' and beyond $(\mathrm{O} / \mathrm{E} 2 \cdot 8)$. There has also been a tendency for the later cases to be older. These 
trends have been noted by Kinlen and interpreted as due to specific local aspects of population mixing. While Kinlen provides an intriguing possible explanation of the excess incidence in the early $1980 \mathrm{~s}$, the strength of evidence for population mixing in the aetiology of the later cases is difficult to evaluate.

A more general hypothesis relating high rates of childhood leukaemia, particularly acute lymphoblastic leukaemia, to conditions of rural isolation and high socioeconomic status has been suggested by Alexander et $a l^{15}$ and Greaves and Alexander. ${ }^{16}$ It is argued that high risk of acute lymphoblastic leukaemia in such populations is related to immunological isolation in infancy and subsequent late exposure to an infectious agent(s) before the appearance of leukaemia. ${ }^{16}$ In sparsely populated areas isolated from urban centres, Alexander et al found an exaggerated age incidence peak of acute lymphoblastic leukaemia in very young children ${ }^{15}$ and a relatively low incidence in older children and young adults. ${ }^{17} \mathrm{~A}$ similar pattern can be seen in the data for the 'full neighbouring area' (fig 2). In the 'full Dounreay area' there was also a pronounced peak incidence in the age group $0-4$ years. In contrast to the 'full neighbouring area', however, there was also an excess of cases in the 5-24 age group in this area within $25 \mathrm{~km}$ of Dounreay. These seven cases (three acute lymphoblastic leukaemia, two acute myeloblastic leukaemia, two non-Hodgkin's lymphoma) occurred from 1980 onwards. The recent study of the distribution of cases near Sellafield also reported an unusual age distribution in comparison with UK data. ${ }^{6}$ The distribution of diagnostic subtypes of the cases in the 'full Dounreay area' was similar to that for Scotland as a whole.

The findings of Kinlen, Alexander et al, and Greaves suggest an infectious component in the aetiology of childhood leukaemia and indicate that certain conditions of rural isolation and population mixing or socioeconomic status, or both, are likely to moderately increase risk. These population characteristics are present in the vicinity of Dounreay but also in other parts of the north of Scotland. The aetiology of childhood and young adult leukaemia and non-Hodgkin's lymphoma is likely to be multifactorial and in this context a generalised interpretation of the present results might be that the Dounreay area is one of underlying high risk of childhood leukaemia where as yet unidentified local factors may also be operational.

We thank the Regional Cancer Registries in Scotland and the many organisations and individuals who contribute to the national cancer registration system, coordinated by Dr CS Muir and Mrs J Crichton. We thank Dr JA Clarke for the provision of hospital discharge data, Dr GJ Draper and Dr C Stiller of the Childhood Cancer Research Group for ata from the National Registry of Childhood Tumours, and $\mathrm{Dr}$ Richards for Richards for data from the MRC Clinical Trials Service Uni Database, Radcliffe Infirmary, Oxford. We are grateful to D FE Alexander and Dr GJ Draper who kindly commented on an earlier version of the paper. Special thanks are
Finlayson for assistance with data processing.

1 Bell AG. Report of the Dounreay EDRP public local inquiry relating to the planning application for the siting of the European demonstration plant (EDRP) for fast reactor
fuel. Caithness, 7 April-25 November 1986. Edinburgh: fuel. Caithness, 7 Ap
Scottish Office, 1989.

2 Heasman MA, Urquhart JD, Kemp IW, Black RJ. Childhood leukaemia in northern Scotland. Lancet 1986;i:266 and 355 .

3 Committee on Medical Aspects of Radiation in the Environment (COMARE). Second Report. Investigation of the possible increased incidence of leukaemia in young people near the Dounreay Nuclear Establishment, Caithness, Scotland. London: HMSO, 1988.

4 Black RJ, Urquhart JD, Kendrick SW, Bunch KJ, Warner $J$, Adams Jones D. Incidence of leukaemia and other cancers in birth and school cohorts in the Dounreay area. BMF 1992;304:1401-5.

5 Urquhart JD, Black RJ, Muirhead MJ et al. Case-control study of leukaemia and non-Hodgkin's lymphoma in children in Caithness near the Dounreay nuclear installachildren in Caithness near the
tion. BMF 1991;302:687-92.

6 Draper GJ, Stiller CA, Cartwright RA, Craft AW, Vincent TJ. Cancer in Cumbria and in the vicinity of the Sellafield TJ. Cancer in Cumbria and in the vicinity of the Sellafic

7 Stiller CA, Kemp I, Draper GJ et al. United Kingdom Scotland: National Registry of Childhood Tumours, 1971-80. In Parkin DM, Stiller CA, Draper GJ, Bieber $\mathrm{CA}$, Terracini B, Young JL (eds). International incidence of childhood cancer. Lyon: IARC, 1988. IARC Scientific Publications no 87.

8 Glass S, Gray M, Eden OB, Hann IM. Scottish validation study of cancer registration data for childhood leukaemia 1968-81. Leuk Res 1987;2.10:881.

9 Registrar General, Scotland. Annual reports. Edinburgh: HMSO, 1968-91.

10 Black D. Investigation of the possible increased incidence of cancer in West Cumbria. London: HMSO, 1984.

11 Gardner MJ, Snee MP, Hall A, Powell CA, Downes S Terrell JD. Results of a case-control study of leukaemia and lymphoma among young people near the Sellafield and lymphoma among young people near the Sellafie

12 Kinlen L. Evidence for an infective cause of childhood leukaemia: a comparison of a Scottish new town with nuclear reprocessing sites in Britain. Lance 1988 ;ii:1323-7.

13 Kinlen L, Clarke K, Hudson C. Evidence from population mixing in British new towns 1946-85 of an infective basis for childhood leukaemia. Lancet 1990;336:577-82.

14 Kinlen LJ, O'Brien F, Clarke K, Balkwill A, Matthews F. Rural population mixing and childhood leukaemia: effects of the North Sea oil industry in Scotland, including the area near Dounreay nuclear site BMF 1993;306:743-8.

15 Alexander FE, McKinney PA, Ricketts TJ, Cartwright RA Community lifestyle characteristics and risk of acute lymphoblastic leukaemia in children. Lancet 1990; 336:1461-6.

16 Greaves MF, Alexander FE. An infectious etiology for common acute lymphobastic leukaemia in childhood. common acute lymphobastic

17 Alexander FE, Ricketts TJ, McKinney PA, Cartwright RA Community lifestyle charateristics and lymphoid malig nancies in young people in the UK. Eur $\mathcal{F}$ Cancer 1991;27:1486-90. 